\title{
PENURUNAN HALUSINASI PADA KLIEN JIWA MELALUI COGNITIVE BEHAVIOR THERAPHY
}

\author{
Sri Eka Wahyuni ${ }^{12^{*}}$, Budi Anna Keliat ${ }^{3}$, Yusron ${ }^{4}$, Herni Susanti ${ }^{3}$ \\ 1. Fakultas Keperawatan Universitas Sumatera Utara, Medan 20155, Indonesia \\ 2. Program Studi Magister Fakultas Ilmu Keperawatan Universitas Indonesia, Depok 16424, Indonesia \\ 3. Fakultas Ilmu Keperawatan Universitas Indonesia, Depok 16424, Indonesia \\ 4. Fakultas Kesehatan Masyarakat Universitas Indonesia, Depok 16424, Indonesia \\ *Email:eka_rizky06@yahoo.co.id
}

\begin{abstract}
Abstrak
Salah satu cara mengatasi halusinasi adalah dengan pemberian cognitive behavior therapy (CBT). Penelitian ini bertujuan mengetahui pengaruh CBT terhadap halusinasi klien di sebuah rumah sakit di Medan. Desain penelitian quasi eksperimental dengan jumlah sampel 56 responden. Hasil penelitian menunjukkan adanya perbedaan peningkatan pelaksanaan cara mengontrol halusinasi yang bermakna antara kelompok yang mendapat dan tidak mendapat CBT $(\mathrm{p}<0,05)$. Halusinasi menurun secara bermakna pada kelompok yang mendapat CBT $(\mathrm{p}<0,05)$. Sedangkan pada kelompok yang tidak mendapat CBT halusinasi menurun secara tidak bermakna $(\mathrm{p}>0,05)$. CBT direkomendasikan dilakukan pada klien halusinasi sebagai tindakan keperawatan spesialis.
\end{abstract}

Kata kunci: cara mengontrol halusinasi, cognitive behavior therapy, halusinasi

Abstract

One way of dealing with the provision of hallucination is cognitive behavior therapy (CBT). This study aimed to verify the effect of CBT on patient hallucinations at a hospital in Medan. Quasi experimental designs with a number of samples are 56 respondents. The results showed a difference in improving the implementation of a meaningful way of controlling the hallucinations between groups that received and did not receive $C B T(p<0,05)$. Hallucinations were significantly decreased in the group receiving $C B T(p<0,05)$, while in the group who did not receive CBT decreased hallucinations was not significant ( $p>0,05)$. CBT is recommended in patients with hallucinations as a specialist nursing intervention.

Keywords: way of controlling hallucinations, cognitive behavioral therapy, hallucination

\section{Pendahuluan}

Salah satu gejala positif yang sering pada klien skizofrenia adalah halusinasi. Menurut Stuart dan Laraia (2005), yang menyatakan bahwa 70\% klien skizofrenia mengalami halusinasi. Pada penelitian juga menunjukkan $90 \%$ klien halusinasi mengalami delusi, sedang pada klien delusi hanya $35 \%$ yang mengalami halusinasi. Hal ini didukung oleh Thomas (1991, dalam Mc-Leod, et al., 2006) yang menyatakan halusinasi secara umum ditemukan pada klien gangguan jiwa salah satunya adalah pada klien skizofrenia.

Halusinasi merupakan suatu bentuk persepsi atau pengalaman indera yang tidak terdapat stimulasi terhadap reseptornya. Halusinasi harus menjadi fokus perhatian oleh tim kesehatan karena apabila halusinasi tidak ditangani secara baik, maka dapat menimbulkan resiko terhadap keamanan diri klien sendiri, orang lain dan juga lingkungan sekitar. Hal ini dikarenakan halusinasi dengar klien sering berisikan perintah melukai dirinya sendiri maupun orang lain (Rogers, et al., 1990 dalam Dunn \& Birchwood, 2009). Secara klinik dan evidence base, halusinasi dengar tersebut telah terbukti dapat menyebabkan distress pada individu (Garety \& Hemsley, 1987 dalam Dunn \& Birchwood, 2009).

Distress disebabkan karena frekuensi halusinasi yang sering muncul pada individu setiap harinya, kekerasan dari suara-suara yang didengarnya, isi dari halusinasi dan juga keyakinan klien terhadap isi dari halusinasinya (Dunn \& Birchwood, 2009). 
Selain itu, halusinasi juga sering menyebabkan ketakutan/ kecemasan bahkan depresi pada klien gangguan jiwa. Dunn dan Birchwood (2009) juga menyebutkan $40 \%$ klien skizofrenia mengalami depresi akibat halusinasi dengar yang dialaminya.

Pinikahana, Happell, dan Keks (2003, dalam Stuart \& Laraia, 2005) menyebutkan bahwa sembilan sampai dengan $13 \%$ klien skizofrenia mengalami suicide (bunuh diri). Selain itu, $20-50 \%$ klien skizofrenia melakukan percobaan bunuh diri. Hal tersebutlah yang menyebabkan halusinasi harus ditangani sesegera mungkin karena dampaknya akan menimbulkan masalah yang lebih besar bagi klien maupun oranglain.

Salah satu terapi yang direkomendasikan dalam upaya mengatasi halusinasi adalah Cognitive behaviour therapy. Cognitive behaviour therapy adalah terapi yang digunakan untuk memodifikasi fungsi berpikir, merasa, dan bertindak dengan menekankan pada peran otak dalam menganalisa, memutuskan, bertanya, berbuat dan memutuskan kembali sehingga dengan merubah status pikiran dan perasaannya, klien diharapkan dapat merubah tingkah lakunya dari hal negatif menjadi positif (Oemarjoedi, 2003).

\section{British Association for Behavioural and Cognitive} Psychotherapies (2006) menyatakan cognitive behaviour therapy adalah terapi yang membantu individu merubah cara berfikir dan perilakunya sehingga perubahan itu membuat individu merasa lebih baik, dan terapi ini berfokus pada here and now serta kesulitan yang dihadapi. Dengan demikian cognitive behaviour therapy merupakan suatu terapi yang membantu individu mengevaluasi kembali persepsi, keyakinan, cara berfikir, dan perilaku yang tidak adaptif yang disebabkan oleh masalah yang dihadapinya.

Keefektifan terapi ini telah dibuktikan penelitian Granholm, et al. (2005) yang mengungkapkan bahwa dengan cognitive behaviour therapy pada klien skizofrenia kronis dapat meningkatkan kemampuan koping, mengevaluasi pengalaman yang salah, pencapaian kognitif insight yang baik, meningkatkan fungsi sosial, mengurangi gejala-gejala positif dan negatif seperti halusinasi dan juga delusi. Selain itu cognitive behaviour therapy juga telah terbukti efektif dalam mengobati gejala positif akibat resistennya individu terhadap obat-obatan skizofrenia (Kingdon \& Turkington, 1997). Selain itu, berdasarkan Chan dan Leung (2002), cognitive behaviour therapy juga memberi manfaat dan efek yang positif dalam menurunkan kejadian kekambuhan pada klien gangguan jiwa.

Cognitive behaviour therapy telah terbukti efektif dalam mengurangi gejala skizofrenia khususnya halusinasi. Hal tersebut disebabkan dalam proses pelaksanaannya cognitive behaviour therapy memperkuat keyakinan dan kemampuan klien dalam mengontrol halusinasi yaitu dengan melatih melakukan strategi koping dalam mengontrol halusinasi secara konsisten (Smith, et al., 2003).

Turkington, Kingdon, dan Weiden (2006) juga menyatakan bahwa dengan pemberi-an cognitive behaviour therapy memberikan perubahan yang sangat besar terhadap jumlah dan kekuatan gejalagajala positif. Turkington, Kingdon, dan Weiden (2006) juga menyebutkan bahwa dengan cognitive behaviour therapy dapat menolong gejala-gejala skizofrenia secara efektif. Hasil observasi perawat di United Kingdom menyebutkan ada keuntungan dari pemberian cognitive behaviour therapy dalam mengurangi halusinasi dengar, depresi dan gejala lainnya.

Tujuan penelitian ini yaitu diperoleh gambaran tentang pengaruh cognitive behaviour therapy terhadap tanda dan gejala halusinasi pada klien, pengetahuan dan pelaksanaan cara mengontrol halusinasi di sebuah rumah sakit di Medan.

\section{Metode}

Penelitian ini adalah penelitian quasi experimental dengan metode kuantitatif menggunakan desain "Quasi experimental pre-post test control group" dengan intervensi cognitive behavior therapy pada bulan Februari sampai dengan Juni 2010. Teknik pengambilan sampel secara consecutive sampling. 
Penelitian dilakukan untuk menganalisa halusinasi, pengetahuan, dan pelaksanaan cara mengontrol halusinasi dengan membandingkan pada kelompok yang mendapatkan dan yang tidak mendapatkan cognitive behavior therapy. Pada tiap kelompok berjumlah 28 responden. Analisis statistik yang dipergunakan yaitu univariat dan bivariat dengan analisis dependent dan independent sample $t$ Test serta Chi-square dengan tampilan dalam bentuk tabel dan distribusi frekuensi.

\section{Hasil}

Pada kelompok yang mendapat cognitive behaviour therapy rerata pengetahuan klien dalam mengontrol halusinasi sebelum intervensi rerata 10,36 , dan setelah intervensi naik menjadi menjadi 16,71 . Selanjutnya, berdasar hasil uji statistik disimpulkan ada perbedaan yang bermakna rerata pengetahuan klien dalam mengontrol halusinasi antara sebelum dengan setelah intervensi pada kelompok yang mendapatkan cognitive behaviour therapy ( $\mathrm{p}=$ $0,000 ; \alpha=0,05)$. Kelompok yang tidak mendapat cognitive behaviour therapy didapatkan rerata pengetahuan klien dalam mengontrol halusinasi sebelum intervensi yaitu rerata 8,32 , dan setelah intervensi naik menjadi menjadi 14,25. Selanjutnya berdasarkan hasil uji statistik disimpulkan bahwa ada perbedaan yang bermakna terhadap rerata pengetahuan dalam mengontrol halusinasi antara sebelum dan setelah intervensi pada kelompok yang tidak mendapat cognitive behaviour therapy $(\mathrm{p}=$ $0,000 ; \alpha=0,05)$. Ada perbedaan yang bermakna pada rerata pengetahuan klien dalam mengontrol halusinasi setelah intervensi antara kelompok yang mendapat dan tidak mendapat terapi $(\mathrm{p}=0,000$; $\alpha=0,05)$.

Pada kelompok yang mendapatkan cognitive behaviour therapy rerata pelaksanaan cara mengontrol halusinasi sebelum intervensi rerata 33,21 , dan setelah intervensi naik menjadi menjadi 55,68. Selanjutnya, berdasarkan hasil uji statistik disimpulkan ada perbedaan yang bermakna rerata pelaksanaan cara dalam mengontrol halusinasi antara sebelum dengan setelah intervensi pada kelompok yang mendapat cognitive behaviour therapy $(p=0,000 ; \alpha=0,05)$.

Pada kelompok yang tidak mendapat cognitive behaviour therapy, pelaksanaan cara mengontrol halusinasi sebelum intervensi reratanya yaitu 30,21,

Tabel 1. Analisis Perbedaan Pengetahuan dan Pelaksanaan Cara Mengontrol Halusinasi Sebelum dan Sesudah Intervensi Cognitive Behaviour Therapy

\begin{tabular}{|c|c|c|c|c|c|}
\hline Kelom pok & Kemampuan & $\mathbf{N}$ & Mean & SD & $\mathbf{p}$ \\
\hline Intervensi & $\begin{array}{l}\text { Pengetahuan } \\
\text { a. Sebelum } \\
\text { b. Sesudah } \\
\text { Selisih }\end{array}$ & $\begin{array}{l}28 \\
28\end{array}$ & $\begin{array}{l}10,36 \\
16,71 \\
\mathbf{6 , 3 6}\end{array}$ & $\begin{array}{l}4,466 \\
1,013 \\
\mathbf{4 , 2 7 9}\end{array}$ & $0,000 *$ \\
\hline Kontrol & $\begin{array}{l}\text { Pengetahuan } \\
\text { a. Sebelum } \\
\text { b. Sesudah } \\
\text { Selisih }\end{array}$ & $\begin{array}{l}28 \\
28\end{array}$ & $\begin{array}{c}8,32 \\
14,25 \\
\mathbf{5 , 9 3}\end{array}$ & $\begin{array}{l}4,269 \\
2,914 \\
\mathbf{4 , 7 8 4}\end{array}$ & $0,000 *$ \\
\hline Intervensi & $\begin{array}{l}\text { Pelaksanaan Cara } \\
\text { a. Sebelum } \\
\text { b. Sesudah } \\
\text { Selisih }\end{array}$ & $\begin{array}{l}28 \\
28\end{array}$ & $\begin{array}{l}33,21 \\
55,68 \\
\mathbf{2 2 , 4 6}\end{array}$ & $\begin{array}{l}10,553 \\
12,341 \\
\mathbf{1 7 , 6 1 2}\end{array}$ & $0,000 *$ \\
\hline Kontrol & $\begin{array}{l}\text { Pelaksanaan Cara } \\
\text { a. Sebelum } \\
\text { b. Sesudah } \\
\text { Selisih }\end{array}$ & $\begin{array}{l}28 \\
28\end{array}$ & $\begin{array}{c}30,21 \\
36,79 \\
\mathbf{6 , 5 7}\end{array}$ & $\begin{array}{l}12,749 \\
10,458 \\
\mathbf{1 4 , 5 4 3}\end{array}$ & $0,024 *$ \\
\hline
\end{tabular}


dan setelah intervensi naik menjadi menjadi 36,79. Selanjutnya, berdasar hasil uji statistik disimpulkan bahwa ada perbedaan yang bermakna pada rerata pelaksanaan cara mengontrol halusinasi antara sebelum dengan setelah intervensi pada kelompok yang tidak mendapatkan cognitive behaviour therapy ( $\mathrm{p}=0,024 ; \alpha=0,05)$. Ada perbedaan yang bermakna pada rerata pelaksanaan cara mengontrol halusinasi setelah intervensi antara kelompok yang mendapat dan tidak mendapat cognitive behaviour therapy $(\mathrm{p}=0,000 ; \alpha=0,05)$.

Pada kelompok yang mendapatkan cognitive behaviour therapy rerata halusinasi klien sebelum intervensi 22,75, dan setelah intervensi menurun menjadi menjadi 14,50. Selanjutnya, berdasarkan hasil uji statistik disimpulkan bahwa ada perbedaan yang bermakna pada rerata halusinasi klien antara sebelum dengan setelah intervensi pada kelompok yang mendapat cognitive behaviour therapy $(\mathrm{p}=0,004 ; \alpha=0,05)$. Pada kelompok yang tidak mendapat cognitive behaviour therapy dengan rerata halusiansi sebelum intervensi rerata 18,86, dan setelah intervensi menurun menjadi 16,36. Selanjutnya, berdasar hasil uji statistik disimpulkan bahwa tidak ada perbedaan yang bermakna rerata halusinasi antara sebelum dengan setelah intervensi pada kelompok yang tidak mendapat cognitive behaviour therapy $(\mathrm{p}=0,336 ; \alpha=0,05)$. Tidak ada perbedaan yang bermakna rerata halusinasi setelah intervensi antara kelompok yang mendapat dan tidak mendapat cognitive behaviour therapy $(p=0,510 ; \alpha=0,05)$.

\section{Pembahasan}

Hasil analisis menunjukkan rerata pengetahuan klien mengontrol halusinasi sebelum dilakukan terapi secara keseluruhan 9,34, nilai terendah 0 dan tertinggi 17 . Kesimpulannya rerata pengetahuan klien dalam mengontrol halusinasi bervariasi dari yang rendah sampai tinggi. Rerata pelaksanaan cara mengontrol halusinasi sebelum dilakukan terapi secara keseluruhan 31,71 dengan nilai terendah 19 dan tertinggi 73. Kesimpulannya rerata pelaksanaan cara mengontrol halusinasi bervariasi dari yang rendah sampai yang tinggi, rerata halusinasi klien secara keseluruhan 20,80 dengan nilai terendah 4 dan tertinggi 42. Kesimpulannya rerata halusinasi klien bervariasi dari halusinasi ringan sampai sangat berat.

Pengetahuan klien dalam mengontrol halusinasi merupakan suatu hal yang paling mendasar dalam proses perubahan dari perilaku klien. Tanpa dasar pengetahuan yang kuat, maka perilaku klien yang ditampilkan atau dihasilkan tidak akan bertahan lama. Menurut Notoatmodjo (2007), menyatakan bahwa pengetahuan merupakan hasil dari tahu dan terjadi setelah orang melakukan penginderaan terhadap objek tertentu. Pengetahuan merupakan domain yang sangat penting dalam membentuk tindakan seseorang, sehingga dapat disimpulkan sebelum individu melakukan sesuatu tindakan, individu tersebut harus mengetahui terlebih dahulu manfaat tindakan tersebut bagi dirinya melalui proses pemberian informasi atau peningkatan pengetahuan.

Pernyataan tersebut diperkuat oleh WHO (dalam Notoatmodjo, 2007), yang menyatakan bahwa strategi merubah perilaku individu dikelompokkan menjadi tiga antara lain; menggunakan kekuatan atau kekuasaan, pemberian informasi, dan diskusi partisipasi. Selain itu, pemberian informasi akan meningkatkan pengetahuan individu itu sendiri.

Tabel 2. Analisis Perbedaan Pengetahuan dan Pelaksanaan Cara Mengontrol Halusinasi Setelah Cognitive Behaviour Therapy

\begin{tabular}{llllcc}
\hline Variabel & Kelompok & N & Mean & SD & p \\
\hline Pengetahuan & Intervensi & 28 & 16,71 & 1,013 & $0,000^{*}$ \\
& Kontrol & 28 & 14,25 & 2,914 & \\
\multirow{2}{*}{ Pelaksanaan cara } & Intervensi & 28 & 55,68 & 12,341 & $0,000^{*}$ \\
& Kontrol & 28 & 36,79 & 10,458 & \\
\hline
\end{tabular}


Selanjutnya, pengetahuan yang didapat melalui informasi akan menimbulkan kesadaran dan pada akhirnya individu akan berperilaku sesuai dengan pengetahuan yang dapatnya. Hasil perubahan perilaku itu akan bersifat langgeng karena didasari oleh kesadaran individu sendiri dan bukan karena paksaan.

Asuhan keperawatan pada klien halusinasi baik yang generalis maupun spesialis bertujuan untuk meningkatkan kemampuan klien dalam mengontrol halusinasinya. Menurut Varcarolis (1990), bahwa kemampuan yang harus dimiliki klien meliputi 3 aspek yaitu kognitif, psikomotor dan juga afektif. Kemampuan kognitif meliputi pengetahuan klien dalam hal mengontrol halusinasinya, sedangkan kemampuan psikomotor merupakan pelaksanaan cara mengontrol halusinasi dalam keseharian klien. Ketika perawat melakukan asuhan keperawatan pada klien halusinasi, perawat memberi informasi terlebih dahulu mengenai halusinasi dan cara mengontrol halusinasi, kemudian melatih klien untuk mampu mengontrol halusinasinya secara mandiri.

Peningkatan pengetahuan terjadi karena pada saat pelaksanaan cognitive behavior therapy klien diberi informasi dan belajar keterampilan baru dalam mengontrol halusinasinya. Hal ini sesuai dengan pendapat Oemarjoedi (2003), yang menyebutkan bahwa pada proses cognitive behaviour therapy terdapat proses cognitive behaviour modification. Salah satu dari proses cognitive behaviour modification adalah klien diajarkan keterampilan baru untuk mengatasi masalah secara praktis agar dapat diterapkan dalam kehidupan sehari-hari. Smith, et al. (2003) menyebutkan bahwa proses pelaksanaan cognitive behaviour therapy memperkuat keyakinan dan kemampuan klien dalam mengontrol halusinasi yaitu dengan cara melatih melakukan strategi koping dalam mengontrol halusinasinya secara konsisten.

Selain itu, pada proses cognitive behaviour therapy, klien dipersiapkan agar dapat melakukan intervensi dan memotivasi dirinya sendiri untuk berubah, serta mampu berhadapan dengan kemungkinan resistensi dan relapse melalui pelatihan stress inoculation. Pelatihan ini terdiri dari kombinasi antara pemberian informasi, diskusi, restrukturisasi kognitif, problem solving, relaksasi, pengulangan tingkah laku, monitor diri, instruksi diri, penguatan diri, dan kemampuan dalam merubah lingkungan (Oemarjoedi, 2003).

Bentuk cognitive behavior therapy juga dapat berupa problem solving therapies, coping skills therapies dimana ditekankan pada cara-cara belajar meningkatkan keterampilan adaptif dan asertif dan memperluas kemampuan mengatasi masalah (Sundberg, Winebarger, \& Taplin, 2007). Dari pernyataan tersebut dapat dilihat bahwa dalam proses cognitive behavior therapy terdapat proses belajar antara terapis dan klien, dimana terapis melakukan transfer pengetahuan terhadap klien mengenai bagaimana cara klien mengontrol halusinasinya.

Tabel 3. Analisis Perbedaan Halusinasi Klien Sebelum dan Sesudah Intervensi Cognitive Behaviour Therapy

\begin{tabular}{|c|c|c|c|c|c|}
\hline Kelompok & Kemampuan & $\mathbf{N}$ & Mean & SD & $\mathbf{p}$ \\
\hline Intervensi & $\begin{array}{l}\text { Halusinasi } \\
\text { a. Sebelum } \\
\text { b. Sesudah } \\
\text { Selisih }\end{array}$ & $\begin{array}{l}28 \\
28\end{array}$ & $\begin{array}{c}22,75 \\
14,50 \\
\mathbf{8 , 2 5}\end{array}$ & $\begin{array}{c}11,024 \\
9,946 \\
\mathbf{1 3 , 9 1 7}\end{array}$ & $0,004^{*}$ \\
\hline Kontrol & $\begin{array}{l}\text { Halusinasi } \\
\text { a. Sebelum } \\
\text { b. Sesudah } \\
\text { Selisih }\end{array}$ & $\begin{array}{l}28 \\
28\end{array}$ & $\begin{array}{c}18,86 \\
16,36 \\
\mathbf{2 , 5 0}\end{array}$ & $\begin{array}{c}9,427 \\
10,996 \\
\mathbf{1 3 , 5 1 1}\end{array}$ & 0,336 \\
\hline
\end{tabular}


Hal ini terjadi karena dalam proses cognitive behavior therapy dan asuhan keperawatan umum/ generalis halusinasi terjadi proses latihan. Latihan itu sendiri merupakan suatu hal penting dalam proses pembelajaran. Menurut Notoatmodjo (2007) bahwa latihan adalah penyempurnaan potensi tenaga-tenaga yang ada dengan mengulang-ulang aktivitas tertentu, latihan merupakan kegiatan pokok dalam proses belajar, sama halnya seperti pembiasaan atau pembudayaan. Latihan maupun pembiasan terjadi dalam taraf biologis, tetapi apabila selanjutnya berkembang ke arah psikis maka akan terjadi proses otomatisme.

Proses tersebut menghasilkan tindakan yang tidak disadari, cepat, dan tepat. Pernyataan di atas juga diperkuat oleh pernyataan Bandura (1986, dalam Woolfolk, 2009), yang mengungkapkan bahwa dalam observational learning, terdapat empat elemen penting yaitu meliputi; memperhatikan, menyimpan informasi, menghasilkan perilaku, dan termotivasi dalam mengulangi perilaku. Selain itu, dalam proses menghasilkan perilaku, individu membutuhkan banyak latihan, dan umpan balik, karena akan membuat perilaku menjadi lebih lancar/ mahir.

Proses latihan yang terdapat didalam proses cognitive behaviour therapy dapat meningkatkan pelaksanaan cara mengontrol halusinasi. Menurut Notoatmodjo (2007) bahwa tingkah laku atau psikomotor merupakan hasil dari belajar, serta belajar tidak terlepas dari latihan. Latihan yang terus menerus akan menghasilkan tindakan yang otomatisasi, yaitu tanpa disadari, cepat, dan tepat. Hal ini diperkuat oleh pernyataan D'Zurilla (1988, dalam Sundberg, Winebarger, \& Taplin, 2007) yang menjelaskan bahwa proses latihan keterampilan mengatasi masalah yang terdapat dalam proses cognitive behavior therapy akan meningkatkan kompetensi sosial dan membantu individu mengurangi perilaku maladaptif serta membantu individu dalam mengatasi stress dan masalah baru.

Peningkatan secara bermakna pada pelaksanaan cara mengontrol halusinasi terhadap klien yang mendapat cognitive behavior therapy juga dapat disebabkan dalam proses pembentukan perilaku baru, terapis menerapkan prinsip-prinsip teori belajar dengan memberi penguatan (reinforcement) dan hukuman (punish-ment) (Oemarjoedi, 2003). Penguatan dan hukuman ini dapat menguatkan perilaku yang dihasilkan oleh individu.

Hal ini sesuai dengan penelitian yang dilakukan Jenner, et al. (2006), yang membuktikan bahwa dengan Hallucination Fokuced Integrative yang menggunakan berbagai terapi modalitas seperti cognitive behaviour therapy, pelatihan koping, terapi keluarga, upaya rehabilitasi, intervensi krisis assertive mobile, pemberian antipsikotik bermanfaat dalam mengatasi halusinasi. Barrowclough, et al. (2001) dalam hasil penelitiannya menunjukkan bahwa program perawatan yang terintegrasi antara motivational interviewing, cognitive behaviour therapy, dan terapi keluarga lebih efektif mengurangi gejala positif dan negatif pada klien skizofrenia dibandingkan dengan pada perawatan umum.

Hasil penelitian yang dilakukan oleh Granholm, et al. (2005), yang mengungkapkan bahwa dengan cognitive behaviour therapy pada klien skizofrenia kronis dapat mengurangi gejala positif. Selain itu, penelitian oleh Kingdon dan Turkington (1994), yang menyatakan bahwa cognitive behaviour therapy efektif dalam mengobati gejala positif akibat resistennya individu terhadap obat-obatan skizofrenia.

Tabel 4. Analisis Perbedaan Halusinasi Klien Setelah Cognitive Behaviour Therapy

\begin{tabular}{llcccc}
\hline Variabel & Kelompok & N & Mean & SD & p \\
\hline \multirow{2}{*}{ Halusinasi } & a. Intervensi & 28 & 14,50 & 9,946 & 0,510 \\
& b. Kontrol & 28 & 16,36 & 10,996 & \\
\hline
\end{tabular}


Hasil penelitian ini juga sesuai dengan penelitian yang dilakukan oleh Trower, et al. (2004) dalam Dunn dan Birchwood (2009), yang telah membuktikan bahwa dengan pemberian cognitive behaviour therapy dapat mengurangi kepercayaan terhadap kekuatan halusinasi dan meningkatkan efektifitas interpersonal. Perubahan halusinasi yang tampak setelah pemberian cognitive behaviour therapy adalah menurunnya tanda dan gejala halusinasi klien.

Hasil yang mengacu pada pre-test, didapat rerata skor halusinasi klien 4,8 , tetapi setelah dilakukan cognitive behaviour therapy didapatkan bahwa skor halusinasi menurun menjadi 1,8. Hal ini menunjukkan bahwa cognitive behaviour therapy efektif menurunkan tanda dan gejala halusinasi klien. Selain itu, pada hasil penelitian ini juga didapatkan bahwa dengan cognitive behaviour therapy klien dapat mengurangi frekuensi dan kekuatan halusinasi serta distress dan depresi yang dihadapi klien dalam menghadapi gejala psikotik yang dialaminya.

Hasil penelitian juga menunjukkan bahwa tidak ada perbedaan yang bermakna rerata halusinasi setelah intervensi antara kelompok yang mendapat cognitive behaviour therapy dengan kelompok yang tidak mendapat cognitive behaviour therapy. Hal ini terjadi karena waktu yang singkat dimana halusinasi klien diobservasi kembali setelah 2 (dua) minggu atau selesai intervensi, sehingga belum terjadi proses yang optimal dalam menurunkan skor halusinasi.

Pernyataan tersebut di atas didukung penelitian yang dilakukan oleh $\mathrm{Ng}$, Hiu, dan Pau (2008), tentang observasi yang dilakukan setelah enam bulan pelaksanaan cognitive behaviour therapy. Sedangkan, penelitian oleh Tarrier, et al. (1998) menjelaskan bahwa observasi dilakukan 10 minggu setelah pelaksanaan cognitive behaviour therapy. Artinya, bahwa perlu adanya waktu klien untuk melakukan proses pengulangan perilaku, sehingga perilaku tersebut menjadi budaya bagi klien dan akhirnya secara tidak langsung dapat menurunkan halusinasinya.

\section{Kesimpulan}

Hasil penelitian menunjukkan halusinasi menurun secara bermakna pada kelompok yang mendapat cognitive behaviour therapy sedangkan halusinasi pada kelompok yang tidak mendapat cognitive behaviour therapy menurun secara tidak bermakna. Pengetahuan dan pelaksanaan cara mengontrol halusinasi pada kelompok yang mendapat cognitive behaviour therapy meningkat secara bermakna dan kelompok yang tidak mendapat cognitive behaviour therapy meningkat secara bermakna juga. Secara deskriptif didapat skor peningkatan pelaksanaan cara mengontrol halusinasi pada kelompok yang mendapat cognitive behaviour therapy lebih tinggi dari kelompok yang tidak mendapat terapi (DN, NN, MK).

\section{Referensi}

Barrowclough, C., Haddock, G., Tarrier, N., et al. (2001). Randomized controlled trial of motivational interviewing: Cognitive behavior therapy and family intervention for patients with comorbid schizophrenia and substance use disorders. Am J Psychiatry, 158 (10), 17061713.

British Association for Behavioural and Cognitive Psychotherapies. (2006). Cognitive behaviour therapy. Diperoleh dari http://www.making space.co.uk/document_library/downloads/CBTFACTSHEET.pdf.

Chan, S.W., \& Leung, J.K. (2002). Cognitive behavioural therapy for clients with schizophrenia: Implications for mental health nursing practice. Journal of Clinical Nursing, 11 (2), 214-224.

Dunn, G., \& Birchwood, M. (2009). Improving psychological adjustment following a first episode of psychosis: A randomised controlled trial of cognitive therapy to reduce post psychotic trauma symptoms. Behaviour Research and Therapy, 47, 454-462.

Granholm, E., McQuaid, J.R., McClure, F.S., et al. (2005). A Randomized controlled trial of cognitive behavioralsocial skills training for middleaged and older outpatients with chronic schizophrenia. Am J Psychiatry, 162, 520-529. 
Jenner, J.A., et al. (2006). Hitting voices of schizophrenia patients may lastingly reduce persistent auditory hallucinations and their burden: 18 month outcome of a randomized controlled trial. Canadian Journal of Psychiatry, 51 (3), 169-177.

Kingdon, D., \& Turkington, D. (1994). Cognitive therapy of schizophrenia. New York: Guilford Press.

McLeod, T., Morris, M., Birchwood, M., \& Dovey, A. (2006). Cognitive behaviour therapy group work with voices hearers. British Journal of Nursing, 16 (4), 248-252.

Ng, R.M.K., Hui, L.K., \& Pau, L. (2008). Cognitive behavioural therapy by novices for supervised community hostel residents with treatment resistent schizofrenia in hongkong: A pilot study. Hong Kong Journal of Psychiatry, 18 (2), 49-54.

Notoatmodjo, S. (2007). Promosi kesehatan dan ilmu perilaku. Jakarta: PT. Rineka Cipta.

Oemarjoedi. (2003). Pendekatan cognitive behaviour therapy dalam psikoterapi. Jakarta: Penerbit Kreativ Medika.

Smith, L., Nathan, P., Juniper, U., Kingsep, P., \& Lim, L. (2003). Cognitive Behaviour therapy for psychotic symptoms: A therapists manual. Perth, Australia: Centre for Clinical Interventions.
Stuart, G.W., \& Laraia, M.T. (2005). Principle and practice of psychiatric nursing (8th Ed.). Philadelphia: Mosby, Inc.

Sundberg, Winebarger, \& Taplin. (2007). Clinical psychology. New Jersey: Prentice Hall.

Tarrier, N., Yusupoff, L., Kinney, C., McCarthy, E., Gledhill, A., Haddock, G., \& Morris, J. (1998). Randomised controlled trial of intensive cognitive behaviour therapy for patients with chronic schizophrenia. BMJ, 317 (7154), 303-307.

Trower, P., Birchwood, M., Meaden, A., Byrne, S., et al. (2004). Cognitive therapy for command hallucinations: Randomised controlled trial. The British Journal of Psychiatry, 184, 312320.

Turkington, D., Kingdon, D., \& Weiden, P.J. (2006). Cognitive behavioral therapy for schizophrenia: A review. Am J Psychiatry, 163, 365-373.

Varcarolis. (1990). Foundations of psychitric mental health nursing. United States of America: Saunders Company.

Woolfolk, A. (2009). Educational psychology: Active learning edition. Boston: Pearson Educational, Inc. 